\title{
Towards sustainable food systems: the concept of agroecology and how it questions current research practices. A review
}

\author{
Séverin Hatt ${ }^{(1,2,3)^{*}}$, Sidonie Artru ${ }^{(1,4)^{*}}$, David Brédart ${ }^{(1,5)}$, Ludivine Lassois ${ }^{(1,4)}$, \\ Frédéric Francis ${ }^{(1,2)}$, Éric Haubruge ${ }^{(2)}$, Sarah Garré ${ }^{(1)}$, Pierre M. Stassart ${ }^{(5)}$, \\ Marc Dufrêne ${ }^{(1,6)}$, Arnaud Monty ${ }^{(1,6)}$, Fanny Boeraeve ${ }^{(6)}$
}

(1) University of Liège - Gembloux Agro-Bio Tech. TERRA. AgricultureIsLife. Passage des Déportés, 2. BE-5030 Gembloux (Belgium). E-mail: Severin.Hatt@ulg.ac.be

(2) University of Liège - Gembloux Agro-Bio Tech. Agrobiochem. Functional and Evolutionary Entomology. Passage des Déportés, 2. BE-5030 Gembloux (Belgium).

(3) Chinese Academy of Agricultural Sciences. Institute of Plant Protection. State Key Laboratory for Biology of Plant Diseases and Insect Pests. West Yuanmingyuan Road, 2. 100193 Beijing (China).

(4) University of Liège - Gembloux Agro-Bio Tech. Biosystems Engineering. Forest Resource Management. Passage des Déportés, 2. BE-5030 Gembloux (Belgium).

(5) University of Liège. Campus of Arlon. SEED - Socio-economy, Environment and Development Unit. Avenue de Longwy, 185. BE-6700 Arlon (Belgium).

(6) University of Liège - Gembloux Agro-Bio Tech. Biosystems Engineering. Biodiversity and Landscape. Passage des Déportés, 2. BE-5030 Gembloux (Belgium).

* These authors contributed equally to this paper.

Received on March 30, 2015; accepted on April 11, 2016.

Introduction. Multiple environmental and socio-economic indicators show that our current agriculture and the organization of the food system need to be revised. Agroecology has been proposed as a promising concept for achieving greater sustainability. This paper offers an overview and discussion of the concept based on existing literature and case studies, and explores the way it questions our current research approaches and education paradigms.

Literature. In order to improve the sustainability of agriculture, the use of external and chemical inputs needs to be minimized. Agroecological farming practices seek to optimize ecological processes, thus minimizing the need for external inputs by providing an array of ecosystem services. Implementing such practices challenges the current structure of the food system, which has been criticized for its lack of social relevance and economic viability. An agroecological approach includes all stakeholders, from field to fork, in the discussion, design and development of future food systems. This inclusion of various disciplines and stakeholders raises issues about scientists and their research practices, as well as about the education of the next generation of scientists.

Conclusions. Agroecology is based on the concept that agricultural practices and food systems cannot be dissociated because they belong to the same natural and socio-economic context. Clearly, agroecology is not a silver-bullet, but its principles can serve as avenues for rethinking the current approaches towards achieving greater sustainability. Adapting research approaches in line with indicators that promote inter- and transdisciplinary research is essential if progress is to be made.

Keywords. Alternative agriculture, agrobiodiversity, ecosystem services, socioeconomic organization, marketing channels, interdisciplinary research, participatory approaches, innovation adoption.

Pour des systèmes agricoles et alimentaires durables : le concept de l'agroécologie et comment il questionne les pratiques actuelles de recherche (synthèse bibliographique)

Introduction. De multiples indicateurs environnementaux et socio-économiques montrent que notre modèle agricole et alimentaire actuel doit être repensé. L'agroécologie a été proposée comme un concept prometteur dans le but d'accroitre sa durabilité. Cet article propose un aperçu du concept et le discute sur la base de la littérature existante et de cas d'études, et explore la manière avec laquelle il questionne notre paradigme actuel de recherche et d'enseignement. 
Littérature. Dans le but d'accroitre la durabilité de l'agriculture, il est nécessaire de minimiser l'usage d'intrants externes et chimiques. Les pratiques agroécologiques cherchent à optimiser les processus écologiques permettant de limiter l'usage de ces intrants à travers la fourniture d'une diversité de services écosystémiques. L'adoption de telles pratiques bouscule le système alimentaire actuel, dont la pertinence sociale et la viabilité économique sont par ailleurs critiquées. L'agroécologie propose d'inclure l'ensemble des parties prenantes intervenant de la fourche à la fourchette dans la discussion, la conception et le développement de nos systèmes agricoles et alimentaires futurs. Cette nécessaire intégration de diverses disciplines et divers acteurs questionne les scientifiques dans leurs pratiques de recherche et d'enseignement.

Conclusions. Le concept d'agroécologie montre que nos pratiques agricoles et le système alimentaire ne peuvent pas être dissociés puisqu'ils dépendent tous les deux du contexte naturel et socio-économique dans lequel ils s'insèrent. Il apparait clairement que l'agroécologie n'est pas une solution miracle, mais que ses principes peuvent être utiles pour repenser les systèmes actuels vers plus de durabilité. Pour finir, il est essentiel que les milieux de la recherche développent des indicateurs et des environnements de travail favorisant l'inter- et la transdisciplinarité.

Mots-clés. Agriculture alternative, agrobiodiversité, services écosystémiques, organisation socio-économique, circuit de commercialisation, recherche interdisciplinaire, approche participative, adoption de l'innovation.

\section{INTRODUCTION}

Common practices in the food system, defined as "conventional" (Altieri, 1999; Kremen et al., 2012a), are coming under increasing criticism in western Europe. Historically, conventional agriculture has led to greatly increased yields and growth in agribusiness, flooding supermarkets with processed food products. Nevertheless, issues such as climate change, pollution, the decline in numbers of farmers and in food quality are being addressed, as reported in the International Assessment of Agricultural Knowledge (2009). Voices calling for a revision of the conventional food system in order to achieve greater sustainability have become louder. Agroecology (also sometimes written "agro-ecology") is being promoted as a promising concept in answer to this call.

Stassart et al. (2012) retraced the historical broadening of the scope of agroecology, from a focus on ecological processes in agriculture to socio-ecological processes. Agroecology first emerged in 1928 and evolved during the $20^{\text {th }}$ century as the application of ecological concepts to agricultural practices, with the primary aim of reducing the use of chemical inputs and the impact of agriculture on the environment (Altieri, 1999). Agriculture is responsible for environmental pollution through, for example, greenhouse gas emissions (25\% of the total emissions worldwide; and 9\% in Wallonia, Belgium; Guns, 2008) and the use of chemicals (e.g., pesticides, growth regulators, mineral fertilizers) that are toxic to the environment (Devine et al., 2007) and human health (Baldi et al., 2013). Agroecological principles suggest that we should safeguard local ecological processes that underpin the delivery of ecosystem services (ES) crucial to agricultural activities (e.g., natural soil fertility, biological control), while maintaining the productive function of agriculture (Malézieux, 2012).

Since the start of the $21^{\text {st }}$ century, agroecology has increasingly been seen as a concept dealing with both ecological and human dimensions, thus involving all stakeholders in the food chain, from production to consumption (Francis et al., 2003), with the aim of increasing the social responsibility and economic viability of farmers' activities. In the European Union (EU), the economic viability of farms is questionable because Common Agricultural Policy subsidies account for almost all of a farmer's net income $(86 \%$, 97\% and 90\% on average in Wallonia in 2011, 2012 and 2013, respectively; Service public de Wallonie, 2014). In addition, the large number of suicides among farmers compared with the rest of the population (in France, 20-30\% higher; Bossard et al., 2013) can be seen as a worrying trend in society. There has also been a steady decline in the number of farms and farmers over recent decades (the EU lost 2.5 million farms between 2005 and 2010; Eurostat, 2015). These facts raise questions about both the social relevance and the economic viability of the conventional food system.

In the light of these sustainability challenges, attention has started to focus on agricultural research. The conventional agricultural system is based on the results of disciplinary and reductionist research that have been applied to a large variety of pedo-climatic conditions by changing and homogenizing these systems to meet our needs (Kremen et al., 2012a). The complexity of the issues involved (i.e., environmental, economic, social and health concerns) shows that holistic and decentralized scientific approaches are needed if sustainable systems are to be developed (Méndez et al., 2013; Louah et al., 2015).

The term "agroecology" is now increasingly being used in academic publications (Bellon et al., 2012). There is a large body of work on the ecological principles of agroecology (Malézieux, 2012; Duru et al., 2015) and the socio-economic dimensions of sustainable food systems (e.g. Francis et al., 2003; Gliessman, 2011; Dumont et al., 2016). So far as we know, however, only a few papers (e.g. Stassart et al., 2012) have brought the two dimensions of agroecology 
together and discussed how they could be adapted to support agroecological innovation.

Based on the literature, this paper looks at how agroecology can help in planning and supporting the transition of conventional food systems towards more sustainable ones. In particular, it seeks to answer the following questions. What are the propositions of agroecology in efforts aimed at improving farming practices and designs to increase environmental sustainability of agriculture, the organization of the food system in order to enhance the social and economic sustainability of agricultural product processing, distribution and consumption? How the transition towards agroecological systems challenges current research practices? This last aspect is drawn on the authors' experience of the practical issues, constraints and successes while working within the multidisciplinary research platform "AgricultureIsLife. be" (University of Liège).

\section{AGROECOLOGICAL PRACTICES TO INCREASE ENVIRONMENTAL SUSTAINABILITY}

Since the Green Revolution, conventional agriculture has focused mainly on the production service (i.e., food, feed, forage, fiber and fuel products), often using practices that are highly dependent on anthropogenic external inputs (e.g., chemical fertilizers, pesticides, irrigation based on non-renewable water sources). These practices, however, override the key ecological processes (i.e., biotic and abiotic interactions) that underpin the delivery of ES crucial to the long-term performance of agriculture (e.g., natural soil fertility, biological control, water-holding capacity, resilience to extreme events) and lead instead to serious agricultural disservices (e.g., agrochemical pollution, pesticide poisoning, greenhouse gas emissions) (Zhang et al., 2007).

The ES framework developed through the Millennium Ecosystem Assessment (Reid et al., 2005) shows that a farming system not only provides "output services" (provisioning and cultural ES), but also receives and depends on "input services" (supporting and regulating ES), such as biological control, water purification and nutrient cycling. Through this framework, the development of environmentally sustainable agricultural practices focuses on optimizing the balance between input and output services (Zhang et al., 2007). Wezel et al. (2014a) noted that agroecological practices are "agricultural practices aiming to produce significant amounts of food, which valorize in the best way ecological processes and ES in integrating them as fundamental elements in the development of practices".
Within the ES framework, biodiversity comes as a key concept when setting out agroecological practices (Altieri, 1999; Kremen et al., 2012b; Wezel et al., 2014a; Duru et al., 2015). Three levels of integration can be distinguished: planned, associated and landscape (bio)diversity.

"Planned biodiversity" refers to the biodiversity intentionally introduced by the farmer into the agroecosystem (Altieri, 1999). This biodiversity includes the productive (e.g., cash crop, forage, timber, livestock) and non-productive (e.g., flowers) biota introduced into the system and managed at varying temporal (e.g., rotation, cover crops), spatial (e.g., intercropping, agroforestry, wildflower strips) and ecological (e.g., genetic diversity at the population, variety and species level) scales (Kremen et al., 2012b).

"Associated biodiversity" refers to the biodiversity unintentionally introduced into the agroecosystem (Altieri, 1999). This biodiversity relies on practices that provide favorable habitats for a diversity of aboveand below-ground organisms, attracting them from the surrounding environment. It contributes indirectly to the productive function by enhancing ecological processes, which in turn can provide ES (Tscharntke et al., 2005).

"Landscape diversity" level takes into account the integration of biodiversity through the structure and composition of the surrounding environment (Duru et al., 2015) and sees biodiversity as a function of its relationship with the surrounding landscape.

Agroecological practices integrate these three levels of biodiversity in order to provide synergies between ecological processes and achieve multiple ES delivery within the system.

The link between the principles outlined above and the concrete implications in terms of management strategies at field, farm or landscape scale has been illustrated in detail in the literature with reference to a wide array of agroecological practices (Power, 2010; Kremen et al., 2012a; Wezel et al., 2014a). For example, wildflower strips (planned biodiversity) can be sown along field margins in order to control insect pests (Uyttenbroeck et al., 2016, same issue). The flowers provide a refuge and food resources (nectar and pollen) that benefit insects (associated biodiversity) that can act as pest natural enemies (predators and parasitoids). The ecological process of biological pest control is therefore an input service benefiting farmers by enabling them to reduce their reliance on insecticides (Pfiffner et al., 2009). In terms of agricultural productivity, however, results with regard to final crop yields are still scarce (Tschumi et al., 2016), but product quality would benefit from the reduction in pesticide residues in the food supply for the consumers.

In order to ensure the delivery of these ES, the surrounding landscape needs to be taken into account. 
For example, the mere presence of wildflower strips might not be efficient enough for controlling pests (Pfiffner et al., 2009) because the delivery of this ES depends on the colonization of wildflower strips by insects coming from (semi-) natural habitats in the landscape (e.g., woodlots, perennial grasslands) (Jonsson et al., 2015). The interdependence between landscape and plot scale in order to maintain ES is specific to each practice. For instance, Tamburini et al. (2016) showed that conservation tillage (defined in this paper as the non-inversion of soil, often combined with permanent vegetation cover) could be efficient for maintaining biological pest control even in simplified landscapes.

Both examples illustrate that the efficiency of a practice in the delivery of one or multiple services depends on interactions at different scales. It is therefore necessary to take account of plot management and landscape composition and the processes relevant to the different scales when planning strategies to maximize services.

Furthermore, synergies may appear between practices. It is therefore important to implement multiple agroecological practices in order to optimize ES delivery. For example, in a recent meta-analysis, Pittelkow et al. (2015) revealed that implementing no-tillage alone led to a reduction in crop yield, whereas combining no-tillage with soil cover (by crop residues or cover crops) and crop rotation could increase yield.

Finally, ES resulting from the implementation of one or multiple agroecological practices do not necessarily occur at the same scale as the practice itself or within the same time frame. For example, the implementation of agroforestry (defined as a land-use system that integrates, in the same area, woody elements with crops and/or livestock production; Torquebiau, 2000) will deliver ES at the farm scale because the deep rooting system of the tree and litterfall participates to nutrient cycling and therefore maintains soil fertility (Tsonkova et al., 2012). Other benefits arise on a wider scale through various processes; for example, research has shown that the presence of trees helps with carbon sequestration and thus contributes indirectly to climate change mitigation on a global scale (Jose et al., 2012). Farmers can therefore expect an annual agricultural income from crops and/or livestock, as well as from fruits and/or nuts from the trees and, in the longer term, from the capitalization of the timber.

Despite the potential of agroecological practices in providing ES, there are still some uncertainties. As highlighted by Wezel et al. (2014a), who outlined the advantages and drawbacks of 15 agroecological practices, their effectiveness in providing ES depends greatly on the local context. Local pedoclimatic conditions affect the ecological processes and the economic and societal environments affect the final goods. Given this context-dependent efficiency, farmers' uncertainties lack of scientific knowledge about some ecological process, possible additional costs of equipment, increase in human labor, low commercialization rate of the product, new legislation and so on (Wezel et al., 2014a). Thus, farmers need to develop tailor-made practices adapted to their local context, which often entails going through a lengthy process of trial and error.

\section{ORGANIZING THE FOOD SYSTEM IN ORDER TO INCREASE SOCIAL RELEVANCE AND ECONOMIC VIABILITY}

A production system based on ecological processes instead of inputs, as described above, challenges the entire food system because it results in greater product diversity in space and time (Kremen et al., 2012a). The challenge is particularly high given that the goods produced by agricultural systems are already numerous (i.e., feed, forage, fiber and fuel; Delcour et al., 2014).

With regard to food, the conventional food system, built on the model of supermarkets and controlled by a few transnational food companies, is based on logistic efficiency, product standardization and price competition (Raynolds, 2004). While product standardization became possible through the use of mechanization and external chemical inputs (Marsden et al., 2006), the need for logistic efficiency and price competitiveness led food companies - which drive the food system - to globalize their provisioning, creating competition between farmers and promoting short-term productivity (Kremen et al., 2012a; Rosset et al., 2012). The significant decline in the number of farmers, however, as well as the importance of EU subsidies in farmer income, are indicators of the limits of this economic model for EU agriculture.

It is in this context that the need to design sustainable food systems arose and this issue became an integral part of agroecology. Francis et al. (2003) proposed involving all stakeholders in building such systems: farmers, processors, retailers, consumers, scientists and politicians. As Gliessman (2011) states: "Farmers alone cannot transform the entire food system." The approach was clarified recently through a list of 13 principles on which sustainable food systems are based. These include: environmental equity, financial independence, partnership between producers and consumers and geographic proximity (Dumont et al., 2016).

Among the multiple stakeholders, particular attention has been given to consumers. Involving and educating consumers has been seen as essential for "closing the loop" in the food system (Francis 
et al., 2003). In this context, Community Supported Agriculture (CSA) networks, which have existed for decades, are seen as an advanced model for sustainable food systems (Kremen et al., 2012a). They are built on direct links between farmers and consumers through direct selling at the local scale. They are economically beneficial because they create jobs on farms and assure farm incomes over the longer term (compared with conventional food systems) (Wezel et al., 2014b). Farmer incomes can also increase because there are fewer intermediaries in short-supply chain marketing. In addition, consumers know more about how their food is produced and therefore request and choose food products based on sustainability criteria (Kremen et al., 2012a). Finally, developing short food supply chains to reconnect producers and consumers is seen as an essential aspect of any agroecological transition (Guzmán et al., 2013) and is one of the 13 principles of sustainable food systems listed by Dumont et al. (2016). A recent criticism of the CSA model, however, is that it does not include the stakeholders in the entire food system (Lamine, 2015a). By definition, it bypasses the intermediaries, whereas the transformation process should involve them.

There are other innovative models based on multiple stakeholder involvement. One is the French food cooperative "Biocoop", a network of 345 organic shops (Lamine, 2015b). Unlike traditional supermarkets, Biocoop brings producers, shop managers, employees and consumers together in an "ethical committee". Its role is to establish common guidelines (e.g., prices at which products are bought to producers and processors, and sold to consumers) and to ensure that the common values are respected. Biocoop's current governance has been strengthened by addressing the criticism it faced in the $1990 \mathrm{~s}$, when it grew considerably and developed logistical tools and management strategies that did not appear to differ much from those of the conventional food system. This illustrates the challenge facing sustainable food system initiatives of finding a balance between remaining in a highly competitive food market while conserving core values that differ significantly from those of food companies.

The challenge also lies in informing consumers of the originality of sustainable food systems, compared with the conventional system, especially because of the confusion that can arise when food companies imply, through labeling, that their products derive from sustainable systems. As Warner (2007) highlighted, labels are used in conventional food chains to persuade consumers of product quality, because food scares have become common and face-to-face relationships no longer exist. They are even seen as "initiatives to create ethical space within the marketplace" (Barham, 2002) without transforming it. "Quality" is an ambiguous term, however, its meaning changing over time (Warner,
2007). Whereas food companies try to meet the quality expectations of consumers, a sustainable food system that involves all stakeholders does not need quality labels. For example, information about synthetic pesticide use, animal welfare, production location and human working conditions (i.e., the most important quality criteria for consumers, according to Howard et al., 2010) can be made available through face-to-face relationships in short-supply chains; in systems such as Biocoop, these criteria are discussed by the "ethical committee" and made available through a charter. Transparency in the production and processing steps, as well as democratic governance (two principles of sustainable food systems; Dumont et al., 2016), allow these systems to be highly responsive to stakeholder expectations in terms of quality, which itself can vary from one location to another (Zepeda et al., 2013).

Unlike the conventional food system, these cases show that sustainable food systems can be diverse. Although they adhere to common principles, the way in which they are implemented can vary (Dumont et al., 2016) and thus attract criticism from unsatisfied stakeholders. This decentralized and therefore flexible approach, however, allows a diversity of projects to develop, each of them tailor-made to their local context.

\section{SCIENTIFIC PRACTICES AND AGRICULTURAL INNOVATIONS}

As is clear from the discussion above, natural, social and agricultural sciences are intrinsically intertwined in food production systems and among the stakeholders in those systems. Accompanying agroecological transition therefore throws up new challenges and opportunities for research. Agroecology questions scientists about their research topics, the methods they use and develop, and the results they produce. Rather than saying that research in conventional agriculture using a biotechnological approach is no longer relevant, this section explores more holistic approaches that scientists could use to integrate complexity and uncertainty into their research practices. Not facing these challenges would lock scientific research into a limited range of thought and action, which in turn would hamper agroecological innovation (Vanloqueren et al., 2009).

First, in order to foster innovation, research should draw on several disciplines, in line with the holistic and complex approach of agroecology. This movement is known as "interdisciplinary research", which is research practice that involves several unrelated academic disciplines, each with its own contrasting research paradigm (Baveye et al., 2014). Linking together agricultural, ecological and many other disciplines leads to innovative practices that restore 
ecological regulating processes, which increase the flow of ES and, consequently, reduce farmers' reliance on external inputs. Adding social disciplines provides the opportunity to study the conditions and processes of learning and change, as well as the interdependencies between the diversity of stakeholders in the food system (Lamine, 2015a). Such research highlights, inter alia, the long-term processes of change in farming practices (e.g., Chantre et al., 2014) or the main reasons for a system's irreversibility, also known as the "lock-in effect" (e.g., Stassart et al., 2008a on the Belgian Blue commodity system and Vanloqueren et al., 2009 on genetic engineering). These examples illustrate how this level of understanding facilitates the development of innovative food systems.

Second, the ambition of agroecology to include all stakeholders in the whole food system leads to their iterative involvement in the research process. This research movement is known as "transdisciplinary", defined as participatory research focused on developing practical knowledge in pursuit of worthwhile human objectives (Baveye et al., 2014), whatever the origin of the science involved and the source of knowledge implied. This approach is sometimes also referred to as "action-oriented" or "participatory" research, although there are distinctions between the terms and their interpretation varies among authors (Méndez et al., 2013; Baveye et al., 2014; Scholz et al., 2015).

Such research practices are increasingly being acknowledged as beneficial in many ways. They create research that is relevant to a local context, which is necessary with the agroecological approach as the studied systems are highly context-dependent (Altieri, 1999; Lyon et al., 2011). They also create opportunities for collective social learning by facilitating an exchange of information among stakeholders with differing values, views and mental frameworks (Duru et al., 2015; Vilsmaier et al., 2015). Above all, they address the gap between theoretical scientific questions and everyday problems faced by local stakeholders (Duru et al., 2015), which facilitates the adoption of research outcomes. This enhances the likelihood of innovations being taken up (Biggs et al., 2011; Duru et al., 2011) and empowers participants (Méndez et al., 2013). This type of research has been successful in many transitions to agroecological-based systems, including the transition from a conventional to an organic beef production chain in Wallonia that required overcoming several cognitive, logistical and commercial "lock-ins" (Stassart et al., 2008b). Another example is illustrated by Cuéllar-Padilla et al. (2011), who empowered farmers and supported them in the transition towards organic farming at a time when they had lost control over their marketing processes to transnational intermediaries. Transdisciplinary research is also useful in improving current management, as shown by Duru et al. (2011), who developed an assessment tool with - and for - farmers for the management of permanent grasslands that took account of the wide range of ES provided by such ecosystems. In essence, integrating various knowledge systems (i.e., scientific and practical) enables the contextual socio-ecological complexity to be taken into account while accompanying agroecological transition and developing appropriate tailor-made innovations.

It should be noted that, currently, there is still a debate about the organization of agroecology as a discipline per se or as an inter- or transdisciplinary practice. This debate is similar to the one about sustainability sciences: Do we need to build one overarching scientific discipline that will address the whole spectrum of sustainability issues - or agroecological issues - or is a dynamic contribution through the expression of various knowledge outputs preferable (Dalgaard et al., 2003)? Beyond this epistemological issue, it is argued that, in practice, agroecology requires a variety of sources of information and therefore that inter- and transdisciplinarity practices are complementary ways of learning (Chantre et al., 2014). Indeed, the meta-level of analysis promoted by inter- and transdisciplinarity requires a certain level of disciplinary expertise to build upon.

Despite much evidence of the opportunities for research to adopt an inter- and transdisciplinary approach, challenges remain for scientists when applying these principles in practice. In order to ensure socially robust innovations, time needs to be invested from the outset of the research in setting common research objectives to address a commonly defined problem (Méndez et al., 2013). This time investment can differ between social and natural sciences, because they produce knowledge at different rates. True co-leadership between science and practice is required, where both knowledge systems are rendered visible and integrated in order to achieve greater symmetry between the two (Scholz et al., 2015). Throughout the whole project, regular feedback and discussions need to take place among all stakeholders in order to redirect research or its methodology, if necessary, so as to achieve the objectives of both scientists and practitioners (Cuéllar-Padilla et al., 2011). In essence, communication is essential in order to learn from each other, build a climate of trust and ensure socially robust outcomes (Méndez et al., 2013).

This communication can, however, be hampered because of the variety of stakeholders involved, and hence the variety of (sometimes confronting) worldviews and knowledge systems. Each stakeholder sees a farming system from a different angle, depending on the plurality of the system's elements and context. With regard to scientists' worldviews, Bawden (1997) 
defined three research positions: technocentric, ecocentric and holocentric. Whereas the technocentric position promotes technical solutions, the ecocentric one seeks to manage ecological processes and the holocentric one integrates human processes and their interactions within the natural environment. Disciplines and knowledge systems also have their own traditions, methods, language and frameworks, which can prove difficult to coordinate and hamper discussions (Dalgaard et al., 2003; Vilsmaier et al., 2015). In addition, knowledge is influenced by one's experiences (referred as "grounded knowledge", Ashwood et al., 2014), which further challenges coordination.

Given the challenges of implementing inter- and trans-disciplinary research, we argue that such shift in a researcher's position needs to be supported. A more fundamental and methodological type of research is needed, one that develops methodologies that are readily applicable in inter- and transdisciplinary research, such as "World Café", "Delphi surveys" and "Citizen juries" (Elliott et al., 2005). More importantly, educational programs have a role to play in fostering and conveying these new methods and training scientists in these new approaches. Some academic agroecological programs are based on learning-bydoing pedagogy (Lieblein et al., 2007; Francis et al., 2013), with the students' learning taking place in situ (e.g., farm, rural development organization) and being open-ended (i.e., searching for solutions not already known by professors). Theoretical and methodological approaches from natural and social sciences are progressively introduced to the students, who have to integrate demands from the stakeholders. In this way, students are trained in inter- and transdisciplinary practices to give them the ability to coordinate distinct grounded knowledge through a reflexive process. The contrast with conventional agricultural education systems is obvious: agroecological programs enable students to reconnect with actual conditions in the field, something that has been lost in agricultural academic institutions. They also focus on the system as a whole with a holistic perspective, rather than focusing on narrow segments of the food system (Louah et al., 2015). We believe that there is a need for a thorough reform in agricultural academic institutions where, currently, agroecological approaches play a minor role (DeLonge et al., 2016).

Repositioning the researcher raises further questions about current academic mindsets and institutions. The process of including stakeholders within the definition of the research issue, reflection and action, and of integrating various disciplines, is time-consuming, produces practical knowledge relevant to a specific local area (Cerf, 2011) and leads to multiple research leaders, multiple data owners and multiple author articles. All this ill suits the classical scientific working climate, with its academic performance benchmarks of personal fast accumulation of publication (Daily et al., 1999; Dalgaard et al., 2003; Cowling et al., 2008). Adapting current research context in order to integrate inter- and transdisciplinary research approaches into the development of agroecological innovations is a major challenge, but one that urgently needs to be addressed.

\section{TOWARDS TAILOR-MADE SOLUTIONS RATHER THAN RECIPES}

The term "agroecology" is now widely used, but its meaning differs depending on who is using it. Too often, agroecology is presented with only one of its two major components considered: agricultural practices and food system organization. In addition, some research projects claim to use the concept of agroecology, and yet ignore the holistic approach. In this paper we argue that, within agroecology, agricultural practices and food system organization cannot be dissociated from each other because they are both needed in order to achieve sustainability from field to fork. We also argue that inter- and transdisciplinary approaches are needed in order to address the issues of sustainability.

We have shown, first, that there are practices based on ecological processes that allow the use of external inputs to be reduced and thus increase the environmental sustainability of farming. Second, we have shown that stakeholders in the food system are able to organize themselves in order to safeguard their activities and guarantee the social relevance and economic viability of the practices. It is clear, however, that challenges remain and therefore none of the existing examples should be taken as copy-paste solutions. Agroecology is not about "one-size-fits-all" solutions or clear-cut recipes (Lyon et al.,2011). Rather, it suggests taking into account the natural and socioeconomic environment where the food is produced and calls for the development of innovations within this precise context. We have shown that contextualizing innovation processes can require working across different scales, combining a variety of methods and drawing on various kinds of knowledge because the challenges are often complex. Agroecology therefore requires the involvement of multiple disciplines and stakeholders within the research process. With this research approach, researchers need to adapt the way in which they address the problem: the choice of the methods to use and the scales to work at will depend on the problem they need to address. Similarly, farmers facing problems with crops or livestock need to adapt their practices according to the specific conditions of their farming context (Lyon et al., 2011). 
Overall, in order to re-organize the food system and develop innovations through research, agroecology proposes to first step back and observe the complexity of local conditions before applying general solutions. Contextualization means there can be no silverbullet; every problem requires a tailor-made solution adapted to its specific socio-ecological context. This is why there are numerous examples of agroecological innovations, as well as their shortcomings. These tailor-made solutions, however, are an appropriate way of achieving sustainability in agriculture and in the organization of the food system.

\section{Acknowledgements}

This research was funded by the CARE AgricultureIsLife, University of Liège - Gembloux Agro-Bio Tech, Belgium and the Belgian Fond National de la Recherche Scientifique FNRS.

\section{Bibliography}

Altieri M., 1999. The ecological role of biodiversity in agroecosystems. Agric. Ecosyst. Environ., 74, 19-31.

Ashwood L. et al., 2014. Linked and situated: grounded knowledge. Rural Sociol., 79(4), 427-452.

Baldi I. et al., 2013. Pesticides : effets sur la santé. Paris : INSERM.

Barham E., 2002. Towards a theory of values-based labeling. Agric. Human Values, 19(4), 349-360.

Baveye P.C., Palfreyman J. \& Otten W., 2014. Research efforts involving several disciplines: adherence to a clear nomenclature is needed. Water Air Soil Pollut., 225(6), 1997.

Bawden R., 1997. The community challenge: the learning response. In: Proceedings of the $29^{\text {th }}$ Annual international meeting of the community development society, 27-30 July, 1997, Athens, Georgia.

Bellon S. \& Guillaume O., 2012. L'agroécologie en France, l'institutionnalisation d'utopies. In : Goulet F. et al., eds. L'agroécologie en Argentine et en France - Regards croisés. Paris : L'Harmattan, 55-90.

Biggs D. et al., 2011. The implementation crises in conservation planning: could "mental models" help? Conserv. Lett., 4, 169-183.

Bossard C., Santin G. \& Guseva Canu I., 2013. Surveillance de la mortalité par suicide des agriculteurs exploitants : premiers résultats. Saint-Maurice, France: Institut de veille sanitaire.

Cerf M., 2011. Is participatory research a scientific practice? J. Rural Stud., 27(4), 414-418.

Chantre E. \& Cardona A., 2014. Trajectories of French field crop farmers moving toward sustainable farming practices: change, learning, and links with the advisory services. Agroecol. Sustainable Food Syst., 38(5), 573602 .
Cowling R.M. et al., 2008. An operational model for mainstreaming ecosystem services for implementation. Proc. Natl. Acad. Sci. U.S.A., 105(28), 9483-9488.

Cuéllar-Padilla M. \& Calle-Collado Á., 2011. Can we find solutions with people? Participatory action research with small organic producers in Andalusia. J. Rural Stud., 27(4), 372-383.

Daily G.C. \& Ehrlich P.R., 1999. Managing earth's ecosystems: an interdisciplinary challenge. Ecosystems, 2(4), 277-280.

Dalgaard T., Hutchings N.J. \& Porter J.R., 2003. Agroecology, scaling and interdisciplinarity. Agric. Ecosyst. Environ., 100(1), 39-51.

Delcour A. et al., 2014. État des lieux des flux céréaliers en Wallonie selon différentes filières d'utilisation. Biotechnol. Agron. Soc. Environ., 18(2), 181-192.

DeLonge M.S., Miles A. \& Carlisle L., 2016. Investing in the transition to sustainable agriculture. Environ. Sci. Policy, 55, 266-273.

Devine G.J. \& Furlong M.J., 2007. Insecticide use: contexts and ecological consequences. Agric. Hum. Values, 24(3), 281-306.

Dumont A.M. et al., 2016. Clarifying the socio-economic dimensions of agroecology: between principles and practices. Agroecol. Sustainable Food Syst., 40(1), 2447.

Duru M. et al., 2011. Combiner des recherches en agroécologie et des dispositifs participatifs pour construire des outils d'évaluation des prairies permanentes. Cah. Agric., 20(3), 223-234.

Duru M. et al., 2015. How to implement biodiversity-based agriculture to enhance ecosystem services: a review. Agron. Sustainable Dev., 35, 1259-1281.

Elliott J. et al., 2005. Participatory methods toolkit - A practitioner's manual. Brussels: King Baudouin Foundation; Flemish Institute for Science and Technology Assessment (viWTA).

Eurostat, 2015. Agriculture, forestry and fishery statistics 2014 edition. Luxembourg: Publications Office of the European Union.

Francis C. et al., 2003. Agroecology: the ecology of food systems. J. Sustainable Agric., 22(3), 99-118.

Francis C. et al., 2013. Phenomenon-based learning in agroecology: a prerequisite for transdisciplinarity and responsible action. Agroecol. Sustainable Food Syst., 37(1), 60-75.

Gliessman S., 2011. Transforming food systems to sustainability with agroecology. J. Sustainable Agric., 35(8), 823-825.

Guns A., 2008. Émissions de gaz à effet de serre et de gaz acidifiants du secteur agricole en Région wallonne. In : Carrefour des productions animales. Gembloux, Belgique : CRA-W ; FUSAGx, 14-19.

Guzmán G. et al., 2013. Participatory action research in agroecology: building local organic food networks in Spain. Agroecol. Sustainable Food Syst., 37(1), 127-146. 
Howard P.H. \& Allen P., 2010. Beyond organic and fair trade? An analysis of ecolabel preferences in the United States. Rural Sociol., 75(2), 244-269.

International Assessment of Agricultural Knowledge, 2009. Agriculture at a crossroads. Washington: Island Press.

Jonsson M. et al., 2015. Experimental evidence that the effectiveness of conservation biological control depends on landscape complexity. J. Appl. Ecol., 52(5), 12741282.

Jose S. \& Bardhan S., 2012. Agroforestry for biomass production and carbon sequestration: an overview. Agrofor. Syst., 86(2), 105-111.

Kremen C., Iles A. \& Bacon C., 2012a. Diversified farming systems: an agroecological, systems-based alternative to modern industrial agriculture. Ecol. Soc., 17(4), 44.

Kremen C. \& Miles A., 2012b. Ecosystem services in biologically diversified versus conventional farming systems: benefits, externalities, and trade-offs. Ecol. Soc., 17(4), 40.

Lamine C., 2015a. Full case study report: Biocoop-France, http://orgprints .org/29253, (10.09.2015).

Lamine C., 2015b. Sustainability and resilience in agrifood systems: reconnecting agriculture, food and the environment. Sociol. Ruralis, 55(1), 41-61.

Lieblein G. et al., 2007. Educational perspectives in agroecology: steps on a dual learning ladder toward responsible action. NACTA J., 51(1), 37-44.

Louah L. et al., 2015. Changements de postures du chercheur, de l'agriculteur et de l'enseignant pour l'innovation agroécologique paysanne. Pour, 226, 5-10.

Lyon A. et al., 2011. Farming without a recipe: Wisconsin graziers and new directions for agricultural science. J. Rural Stud., 27(4), 384-393.

Malézieux E., 2012. Designing cropping systems from nature. Agron. Sustainable Dev., 32(1), 15-29.

Marsden T. \& Murdoch J., 2006. Between the local and the global: confronting complexity in the contemporary agri-food sector. Amsterdam, The Netherlands: Elservier JAI.

Méndez V.E., Bacon C.M. \& Cohen R., 2013. Agroecology as a transdisciplinary, participatory, and action-oriented approach. Agroecol. Sustainable Food Syst., 37(1), 3-18.

Pfiffner L. et al., 2009. Impact of wildflower strips on biological control of cabbage lepidopterans. Agric. Ecosyst. Environ., 129, 310-314.

Pittelkow C.M. et al., 2015. Productivity limits and potentials of the principles of conservation agriculture. Nature, 517(7534), 365-368.

Power A.G., 2010. Ecosystem services and agriculture: tradeoffs and synergies. Philos. Trans. R. Soc. London, Ser. B, 365(1554), 2959-2971.

Raynolds L.T., 2004. The globalization of organic agro-food networks. World Dev., 32(5), 725-743.

Reid W. \& Mooney H., 2005. Ecosystems and human wellbeing. Synthesis. A report of the Millennium Ecosystem Assessment. Washington: Island Press.
Rosset P.M. \& Martínez-Torres M.E., 2012. Rural social movements and agroecology: context, theory, and process. Ecol.Soc., 17(3), 17.

Scholz R.W. \& Steiner G., 2015. Transdisciplinarity at the crossroads. Sustainability Sci., 10(4), 521-526.

Service public de Wallonie, 2014. Évolution de l'économie agricole et horticole de la Wallonie 2012-2013, http:// agriculture.wallonie.be/apps/spip_wolwin/IMG/pdf/ rapport2012.pdf, (03.02.2014).

Stassart P.M. \& Jamar D., 2008a. Steak up to the horns! The conventionalization of organic stock farming: knowledge lock-in in the agrifood chain. GeoJournal, 73(1), 31-44.

Stassart P.M., Mormont M. \& Jamar D., 2008b. La recherche-intervention pour une transition vers le développement durable. Écon. Rurale, 306, 8-22.

Stassart P.M. et al., 2012. L'agroécologie: trajectoire et potentiel pour une transition vers des systèmes alimentaires durables. In: Van Dam et al., eds. Agroéocologie: entre pratiques et sciences sociales. Dijon, France : Educagri, 25-51.

Tamburini G. et al., 2016. Conservation tillage mitigates the negative effect of landscape simplification on biological control. J. Appl. Ecol., 53(1), 233-241.

Torquebiau E.F., 2000. A renewed perspective on agroforestry concepts and classification. C.R. Acad. Sci. Ser. III, 323(11), 1009-1017.

Tscharntke T. et al., 2005. Landscape perspectives on agricultural intensification and biodiversity-ecosystem service management. Ecol. Lett., 8(8), 857-874.

Tschumi M. et al., 2016. Perennial, species-rich wildflower strips enhance pest control and crop yield. Agric. Ecosyst. Environ., 220, 97-103.

Tsonkova P. et al., 2012. Ecological benefits provided by alley cropping systems for production of woody biomass in the temperate region: a review. Agrofor. Syst., 85(1), 133-152.

Uyttenbroeck et al., 2016. Pros and cons of flowers strips for farmers. A review. Biotechnol. Agron. Soc. Environ., 20(S1), 225-235.

Vanloqueren G. \& Baret P.V., 2009. How agricultural research systems shape a technological regime that develops genetic engineering but locks out agroecological innovations. Res. Policy, 38, 971-983.

Vilsmaier U. et al., 2015. Case-based mutual learning sessions: knowledge integration and transfer in transdisciplinary processes. Sustainability Sci., 10(4), 563-580.

Warner K.D., 2007. The quality of sustainability: agroecological partnerships and the geographic branding of California winegrapes. J. Rural Stud., 23, 142-155.

Wezel A. et al., 2014a. Agroecological practices for sustainable agriculture. A review. Agron. Sustainable Dev., 34(1), 1-20.

Wezel A. et al., 2014b. The food system approach in agroecology supported by natural and social sciences. In: Benkeblia N., ed. Agroecology, ecosystems and 
sustainability. Boca Raton, FL, USA: CRC Press/Taylor and Francis Group, 181-199.

Zepeda L. et al., 2013. A conceptual framework for analyzing consumers' food label preferences: an exploratory study of sustainability labels in France, Quebec, Spain and the US. Int. J. Consum. Stud., 37, 605-616.
Zhang W. et al., 2007. Ecosystem services and dis-services to agriculture. Ecol. Econ., 64, 253-260.

(66 ref.) 